\title{
Cervical Disc Arthroplasty -Efficacy and Indications. Single Center Long-Term Cohort Study Compared to Rcts' Results
}

\author{
Dariusz Latka $^{1 *}$, Kajetan Latka ${ }^{1}$, Grzegorz Miekisiak ${ }^{1}$, Klaudia Kozlowska ${ }^{2}$, Tomasz Olbrycht ${ }^{1}$ and Jacek \\ Chowaniec $^{1}$
}

${ }^{1}$ Department of Neurosurgery, Institute of Medicine, University of Opole, Poland

${ }^{2}$ Department of Bioengineering, Institute of Biomedical Engineering, Technical University of Wroclaw, Poland

Submission: June 25,2019; Published: July 12, 2019

*Corresponding author: Dariusz Latka, Department of Neurosurgery, Institute of Medicine, University of Opole, Aleja Witosa 26, 45-410 Opole, Poland

\author{
Abstract \\ Purpose: This study aims to compare CTDR and ACDF functional outcomes and to determine whether our criterion to exclude patient from \\ the CTDR cohort positively affects the results.
}

Methods: We have conducted a single-center, prospective, observational study of two cohorts: CTDR $n=88$, and ACDF $n=90$. The choice of the method for the particular patient was not fully random - it depended on the assumed disqualification criterion for CTDR the lack of intraoperatively determined mobility. Both cohorts were clinically followed over the long-term (average: 8 years). Our results were summarized with the results of large randomized studies subjected by our team to a meta-analysis reported in full in separate paper.

Results: The patient-reported clinical evaluations similarly improved in both cohorts at follow-ups. The only noteworthy difference is EQ-5Dindex at 6 months: $\mathrm{CTDR}=0.79$ in compare to $\mathrm{ACDF}=0.85$, correllating with the difference in mean sum of VAS neck pain intensity and frequency scores: $\mathrm{CTDR}=7,1$ and $\mathrm{ACDF}=5,6$. However, the difference was not significant $(p>0,05)$. The frequency of reoperation related to ASD in our study was 1.9\%/level/year in ACDF and 0.6\%/level/year in CTDR. The comparison of all these results with the results of the meta-analysis did not show any statistically or clinically significant differences.

Conclusion: Our study reveals that both methods are functionally effective. On the other hand, the assumed thesis that the lack of intraoperatively observed mobility of the index segment was to constitute a contraindication to CTDR cannot be considered true according to the comparison of our own study and meta-analysis results.

Keywords: Cervical total Disc Replacement; Cervical disc arthroplasty; Anterior cervical discectomy and fusion; Cervical degenerative disc disease; Cervical discectomy; Smith-robinson; Qualification criterion; Demographically; Hypothetical qualification; Neck; Important difference; Same evaluation

Abbreviations: CDTR: Cervical total Disc Replacement; CDA: Cervical disc arthroplasty; ACDF: Anterior cervical discectomy and fusion, CDDD: Cervical Degenerative Disc Disease; ASD: Adjacent Segment Disease

\section{Introduction}

Cervical Degenerative Disc Disease (CDDD) leads to neural structure compression, which may eventually result in radiculopathy. The most common CDDD-related symptom includes neck pain, which is typically associated with shoulder pain. Degenerative disc disease is also one of the main causes of cervical radiculopathy. It is the result of annulus fibrosus degeneration related to aging, which leads to perforations and tears within the disc. The indications for surgery in these cases include adequate visualization with diagnostic imaging, symptoms persistence for six weeks, and resistance to conservative treatment and/or progressive motor deficit that affects normal functioning $[1,2]$.

Anterior Cervical Discectomy and Fusion (ACDF) has been regarded as the standard technique used in the surgical treatment of Cervical Degenerative Disc Disease (CDDD) since 1955 at which point it was first introduced and then described by Smith and Robinson [3]. With a few modifications, it has become the gold standard among spine surgeons [1]. The fusion can be achieved in various ways, including auto- or heterogeneous bone 
grafts and/or the use of intervertebral implants made of various materials. An interesting modification of ACDF is the resorbable cage application. The resorbable cages, which are usually made of calcium lactate, are often filled with bone graft substitutes (such as calcium phosphate and/or hydroxyapatite). The mode of one of these cage's action is to support the segment height while bony fusion is promoted through the central void filled with grafting material [4]. However, ACDF, as with any surgery regardless of the way it is performed, involves possible adverse effects [5].

One of the most well-known adverse effects appears to be Adjacent Segment Disease (ASD). This effect is a degeneration of the segment adjacent to the level that underwent the operation and is likely due to changes in the distribution of biomechanical forces after fusion [6-8]. The incidence of ASD requiring further surgery ranges from $2 \%$ to $4 \%$ /year/level [9]. During the last two decades, so called Cervical Disc Total Replacement (CDTR) or Cervical Disc Arthroplasty (CDA) with mobile prostheses has become another very promising alternative for ACDF. It maintains the operated segment's mobility and could probably protect it from ASD [10]. In order to compare the results of treatment after using both modern techniques, we planned a single-center, prospective, observational cohort study. Our study aimed to prospectively investigate the functional outcomes of Cervical Disc Total Replacement (CDTR) versus anterior cervical discectomy and fusion (ACDF) using resorbable intervertebral cages for the treatment of one or two levels of symptomatic CDDD at early to mid- to long-term follow-up. After that, our results were compared to RCTs meta-analyzed in the literature.

\section{Material and Methods}

This prospective cohort study consisted of two series of patients with one or two levels of CDDD who underwent surgery at one center during the period between November 2004 and March 2009. All of the patients were operated on by the same group of surgeons using the standard Smith-Robinson anterior approach and a microsurgical technique for discectomy in all cases. Each patient received either a Solis (Stryker, USA) resorbable cage implant (ACDF group) or a Prestige LP (Medtronic, USA) cervical disc prosthesis (CDTR group). A total of 178 patients were included in one of two cohorts and who had been treated either with a Prestige LP cervical disc prosthesis (up to 88 patients) or Anterior Cervical Discectomy and Fusion (ACDF) using a Solis resorbable cage implant (up to 90 patients). The choice of the method was not fully random; it depended on the assumed qualification criterion for arthroplasty in which lack of mobility found intra-operatively excluded the patient from the CDTR cohort and forced the surgeon to perform fusion. That is probably the reason that the cohorts were not equal demographically.

The ACDF group was almost ten years older, and patients qualified to enter this cohort probably presented with the more rigid, spondylotic CDDD variation. This difference between our series and fully randomized series from RCTs available in literature and reported by our team in a separate paper [11] prompted us to compare results to look for an answer to the question of whether our results are better for demonstrating that the hypothetical qualification criterion for CDTR applied at our institution was properly achieved. Both cohorts were clinically followed and compared at three, six, 12 , and 48 months and afterwards surveyed by mail for long-term evaluation ( $>8$ years). Functional evaluation included the Neck Disability Index (NDI), visual Analog Scale (VAS) scores for neck and/or arm pain, and EuroQol measurements (either EQ-VAS or EQ-5D3L). We also analyzed the differences in the resulting parameters in relation to their corresponding baselines to be compared with the values of the smallest change in the clinical parameters that the patient would consider significant (Minimal Clinically Important Difference [MCID]) derived from literature [12-15].

Compliance with this follow-up in the CDTR and ACDF groups at three, six, 12, and 24 months was $93.2 \%(82 / 88)$ and $85.6 \%$ (77/90), 78.4\% (69/88) and 46.6\% (42/90), 70.5\% (62/88) and 43.3\% (39/90), 59\% (52/88) and 41.1\% (37/90), respectively. The long-term survey at a mean of eight post-operative years was answered by $55.7 \%$ (49/88) and 48.9\% (44/90) of patients in the CDTR and ACDF groups, respectively Table 1.

Table 1: Summary of patients' demographic characteristics in both cohorts.

\begin{tabular}{|c|c|c|}
\hline & CDA & ACDF \\
\hline No. of patients & 88 & 90 \\
\hline male /female ratio & $19 / 69$ & $36 / 54$ \\
\hline mean age/range & 41,9 yrs (SD=7,2) & $51,2 \mathrm{yrs}(\mathrm{SD}=5,8)$ \\
\hline $\begin{array}{c}\text { Single level /two- } \\
\text { level }\end{array}$ & $79 / 9$ & $72 / 18$ \\
\hline C3/4 & 2 & 3 \\
\hline C4/5 & 6 & 12 \\
\hline C5/6 & 62 & 55 \\
\hline C6/7 & 27 & 38 \\
\hline
\end{tabular}

There were 19 male and 69 female patients in the CDTR group, and the average age of the cohort was 41.9 years \pm 7.2 years. One level CDDD was treated in 79 patients, and two levels in nine patients. Sixty-two patients received surgery at the C5/C6 level, 27 at the C6/C7 level, six at the C4/C5 level, and two at the C3/C4 level. There were 36 male and 54 female patients in the ACDF group, and the average age of the cohort was 51.2 years \pm 5.8 years. Seventy-two patients received treatment for one level while 18 patients underwent treatment for two levels. Fifty-five patients underwent an operation at the C5/C6 level, 38 patients underwent one at the C6/C7 level, 12 patients underwent an operation at the $\mathrm{C} 4 / \mathrm{C} 5$ level, and three patients underwent one at the C3/C4 level. Over the course of the follow-up period, we have registered 17 re-operations due to adjacent segment disease. Fourteen of these patients came from the ACDF group, 
and the average interval between operations was 24.0 months. The remaining three patients belonged to the CDTR group and underwent subsequent surgeries at an average interval of 82.5 months after the primary operations. We tested the data statistically using the Shapiro-Wilk test. Further analyses were performed using the Mann-Whitney test.

\section{Results}

The patient-reported outcomes were similar in both cohorts, particularly with respect to the EQ-VAS and neck/arm VAS scores. All of the patients exhibited statistically significant improvement during all of routine 3-, 6-, 12-, and 24-month follow-up evaluations and at the long-term follow-up. Favorable outcomes were observed with either the EQ-5D index or EQ-VAS and NDI. The only noteworthy difference in functional outcomes between the CDTR and ACDF groups was the EQ-5D index at six months, which was 0.79 for CDTR compared with 0.85 for the ACDF group. The difference was not statistically significant ( $p>0.05$ ). The difference in the mean value of VAS neck pain intensity and frequency scores over the same evaluation period was also not statistically different (7.1 and 5.6, respectively) ( $p$ $>0.05$ ) (Figure 1).

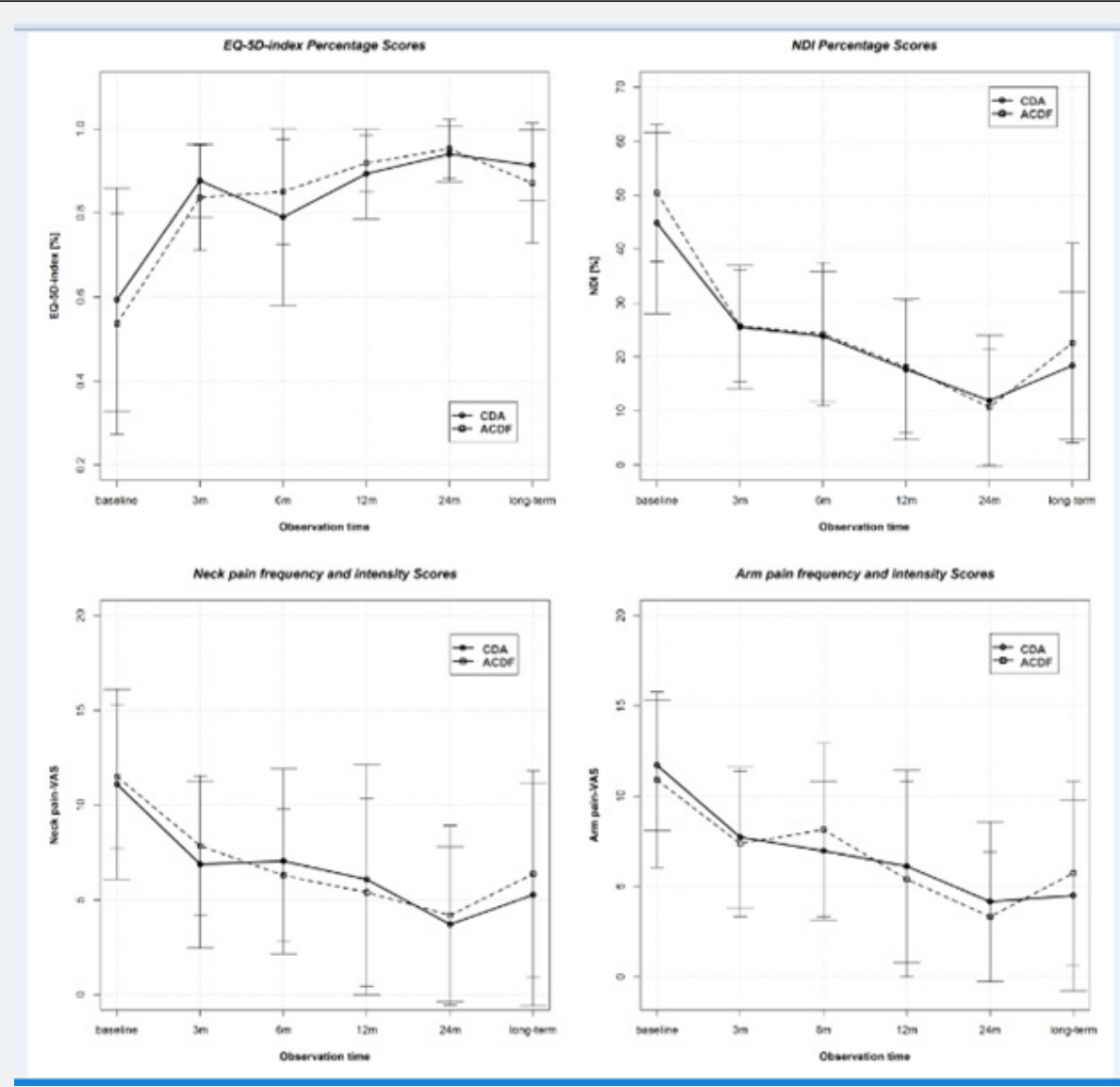

Figure 1: Comparisons of pre- and post-operative outcome factors examined in both cohorts at follow-up time points.

Twenty-four months after the operation, nine ASD cases out of the 90 ACDF patients and no ASD cases in the CDTR group were observed in our series. The resulting odds ratio was 0.05 with $95 \%$ confidence Interval (CI) equal $(0.00 ; 0.94)$. This result was in line with the majority of prospective randomized trials analyzed by our group and in those reported in a separate meta-analysis [11] in which the odds ratio was $<1$ and should be interpreted as a lower chance of ASD in the CDTR than ACDF group (Figure 2). Most CIs of the analyzed papers and the total result of the meta-analysis exceeded line one, so the real effects could have a value above one [16-23]. Papers with narrower confidence intervals, including larger samples, also indicated a lower chance of ASD in the ACDF group although among them, line 1 was exceeded.
During the long-term follow-up at our institution (up to eight years), we conducted 13 secondary surgeries at adjacent levels in the ACDF group and four secondary surgeries at adjacent levels in the CDTR group (Figure 2). The resulting odds ratio had a value of 0.28 with a $95 \%$ CI equal to $(0.09 ; 0.91)$. This result was also in line with the majority of the examined RCTs in which the odds ratio was $<1$, which should be interpreted as a lower chance of developing ASD in the CDTR group than in the ACDF group [18, 24-26]. Apart from one case [24], the Cis of the analyzed reports and the total meta-analysis result did not exceed the one line. In comparison to the analyzed ASD 24 months after surgery, for data $>60$ months, a clear advantage of the CDTR with respect to ASD was observed (Figure 2). 

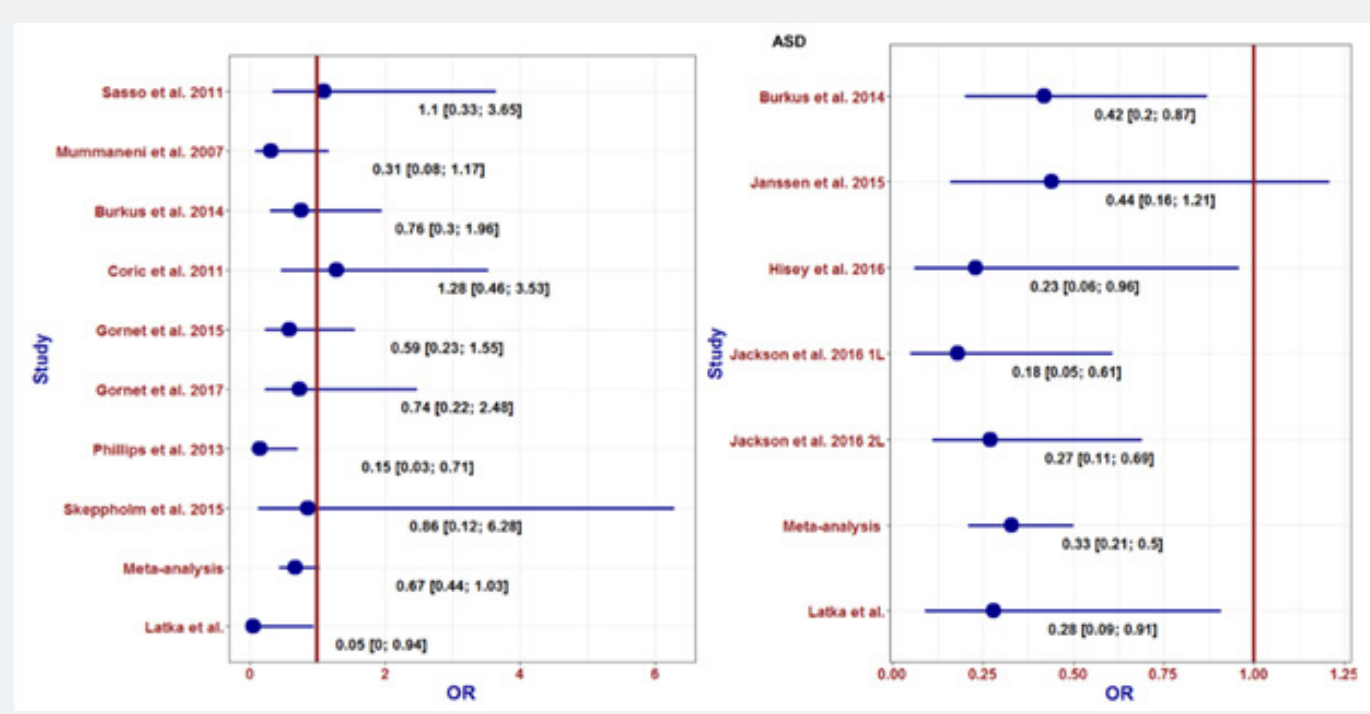

Figure 2: Symptomatic ASD in 24-month follow-up (left panel) and 60-month follow-up (right panel).

Twenty-four months after the operation, the average difference between CDTR and ACDF for the NDI parameter was 1.18 with a $95 \% \mathrm{CI}$ of $-2.18 ; 4.54$ (Figure 3 ). This resulted in higher NDI values for the CDTR; therefore, the patients treated with ACDF presented greater NDI benefits. This result was not consistent with the results obtained on the basis of the RCTs' analysis and combined effects of the meta-analysis $[16,18,23,27,28]$. In most of the analyzed papers, the average difference was $<0$, which would indicate an advantage to using the CDTR method. An accurate analysis was complicated by wide and overlapping CIs.
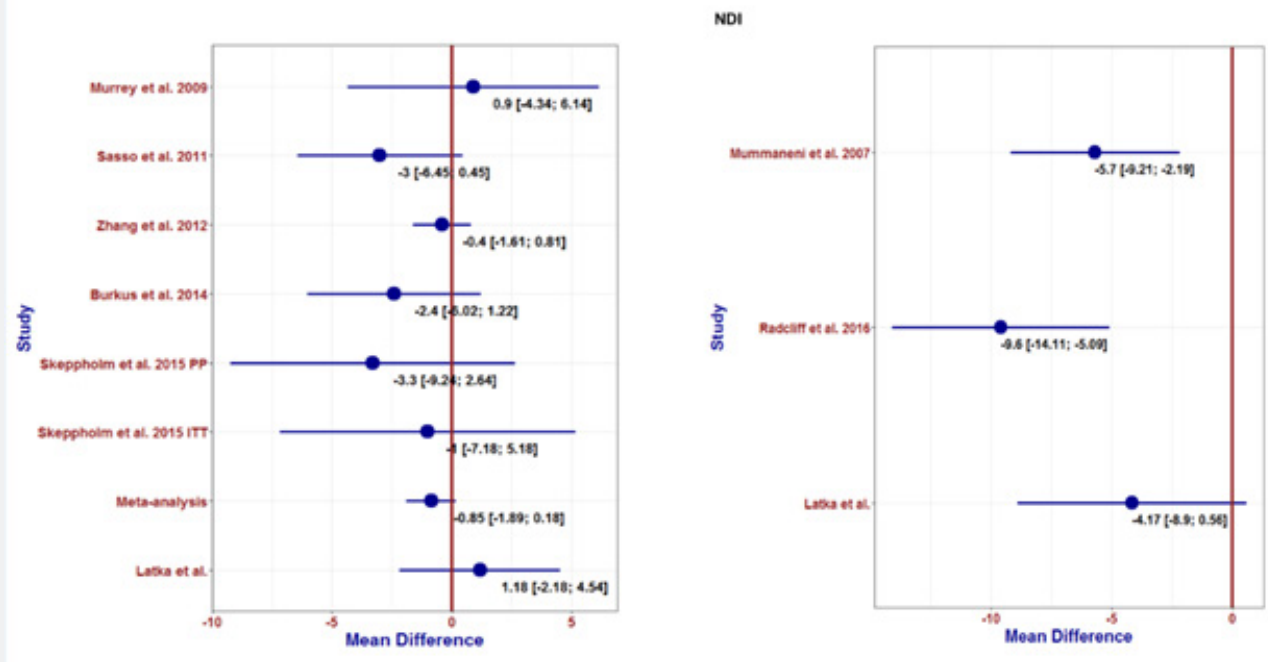

Figure 3: NDI in 24-month (left panel) and 60-month follow-up (right panel).

In our data for long-term observation, the average difference between CDTR and ACDF cohorts for the NDI parameter was -4.17 with a $95 \%$ CI of $-8,90 ; 0.56$ (Figure 3 ). This resulted in higher NDI values for the ACDF method; therefore, the patients treated with CDTR presented greater benefits with respect to the NDI. This result was in line with the results obtained on the basis of RCT analysis, for which the CIs did not exceed the zero line $[17,29]$. It should be mentioned that the work of Radcliff et al. included two-segment operations [29]. An accurate analysis was complicated by wide and overlapping CIs and the small number of included papers.

Twenty-four months after the operation, the average difference between CDTR and ACDF cohorts for the VAS neck parameter was -0.47 with a $95 \%$ CI of $-1.77 ; 0.83$ (Figure 4). This resulted in higher VAS neck values for the ACDF; therefore, the patients treated with CDTR presented greater benefits with respect to NDI. This result was in line with the results obtained 


\section{Open Access Journal of Neurology \& Neurosurgery}

on the basis of the collected RCT analysis and the combined effect of their meta-analysis $[16,18,23,28]$. In most papers, the average difference was $<0$, which would indicate an advantage of using the CDTR method. An accurate analysis was complicated by wide and overlapping CIs. In our long-term observation data, the mean difference between CDTR and ACDF cohorts for the
VAS neck parameter was -1.10 with a $95 \%$ CI of $-2.75 ; 0.54$ (Figure 4). This resulted in higher VAS neck values for the ACDF; thus, the patients treated with CDTR benefited more from using the VAS neck score for the evaluation. This result was in line with the results obtained on the basis of the analysis of two analyzed RCTs; for them, the CIs did not exceed the zero line [17, 29].
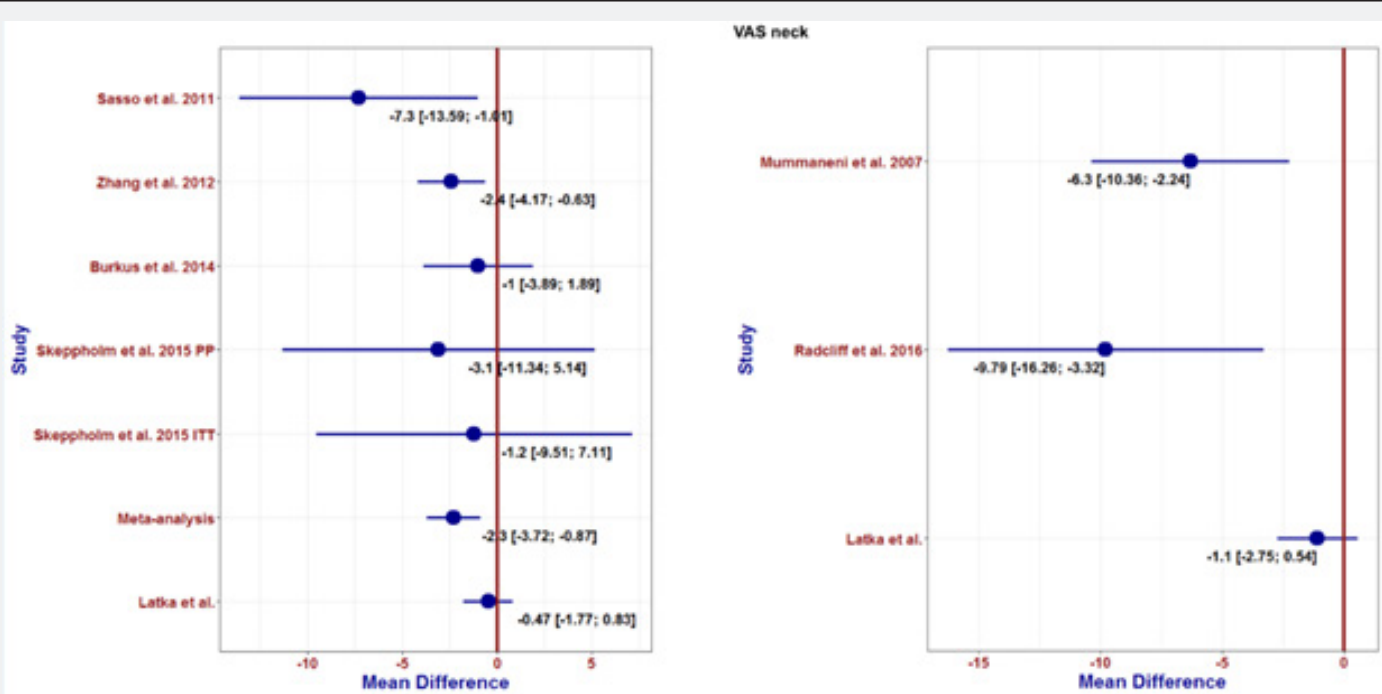

Figure 4: VAS neck at the 24-month (left panel) and 60-month follow-ups (right panel).

Twenty-four months after the operation, the average difference between CDTR and ACDF cohorts for the VAS arm parameter was 0.83 with a 95\% CI of $-0.35 ; 2.01$ (Figure 5). This resulted in higher VAS neck values for the CDTR method; therefore, the patients treated with ACDF had greater benefits with respect to the VAS arm. This result was not consistent with the results obtained on the basis of the analysis of the collected works and the combined effect of the meta-analysis $[16,18,23,28]$. In most studies, the average difference was $<0$, which would indicate an advantage to using the CDTR method. An accurate analysis was complicated by wide and overlapping CIs.
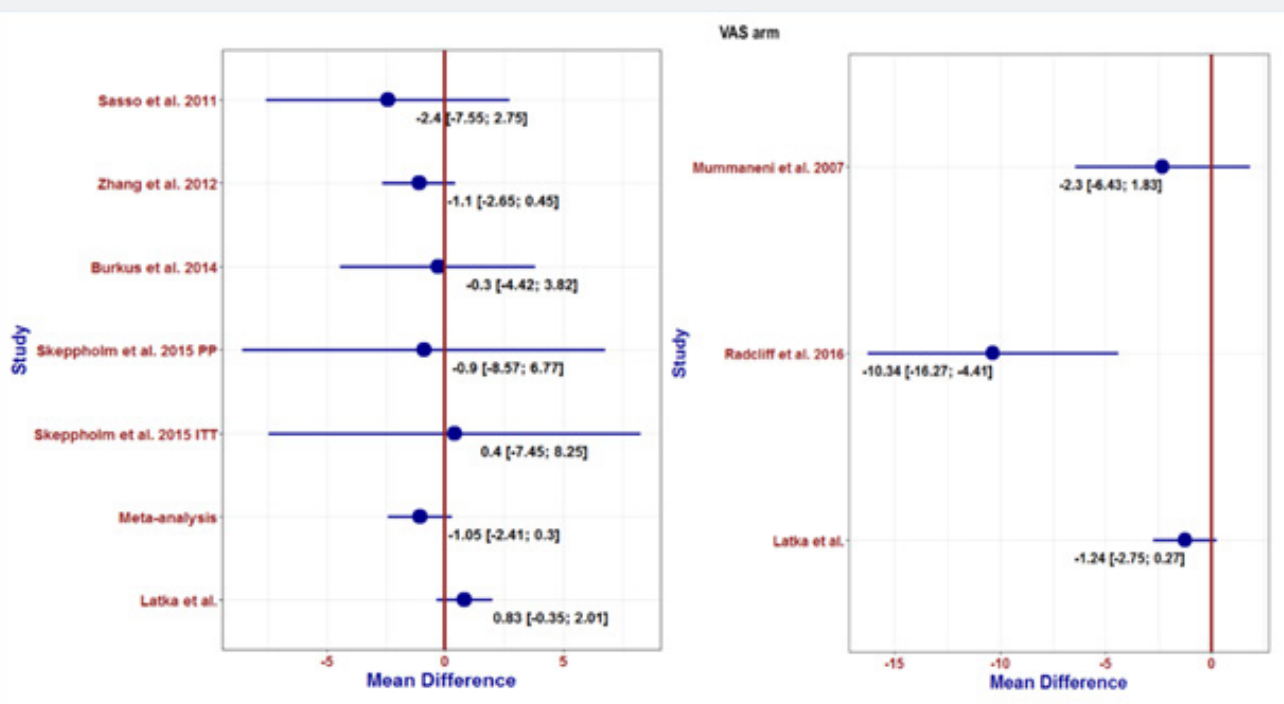

Figure 5: VAS arm in the 24- (left panel) and 60-month follow-ups (right panel).

In our long-term observation data, the average difference between CDTR and ACDF for the VAS arm parameter was -1.24 with a $95 \%$ CI equal to $-2.75 ; 0.27$ (Figure 5). Such a result indicated higher VAS arm values for the ACDF; therefore, the patients treated with CDTR benefited more from the VAS arm. This result was in line with the results obtained on the basis 


\section{Open Access Journal of Neurology \& Neurosurgery}

of the analysis of the two collected works $[17,29]$. It should be mentioned that the work of Radcliff et al. included two-segment operations, and only for this work did the CI exceed the zero line [29]. An accurate analysis was complicated by wide and overlapping CIs and the small number of included papers.

In our series, the mean difference between the values of the NDI parameter in the pre- and post-operative CDTR and ACDF groups was -2.88 with the $95 \%$ CI equal to -9.36 ; 3.60 (Figure 6). This resulted in higher NDI differences for the ACDF; therefore, the patients treated with ACDF presented greater NDI benefits. This result was not consistent with the results obtained on the basis of the RCT analysis and the combined effect of their metaanalysis [24,28,30,31]. In most papers, the average difference in differences was $>0$, which would indicate an advantage to using the CDTR method. The difference between pre- and postoperative values in the NDI parameter range for the group did not exceed the MCID threshold determined on the basis of data from the literature [12-15].

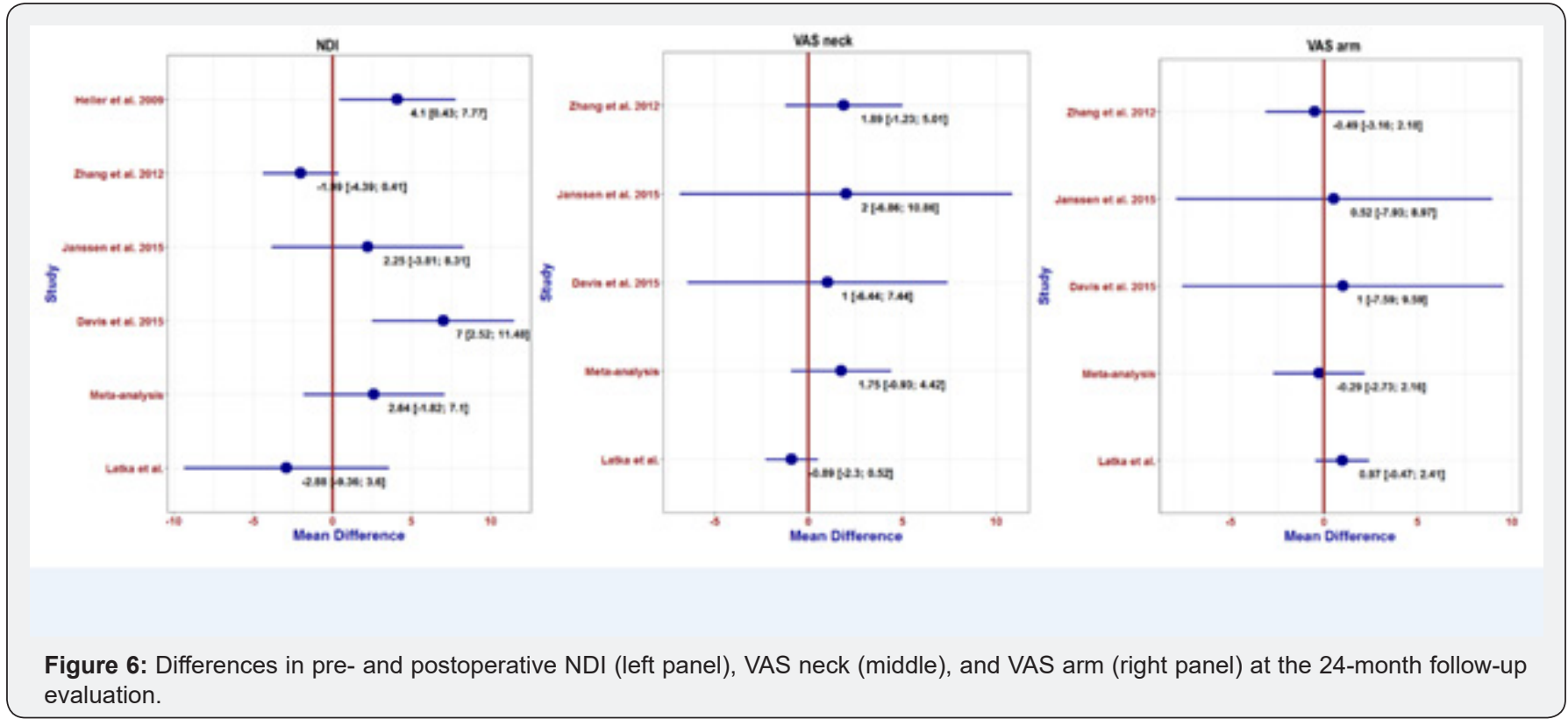

In our series, the mean difference between the values of the VAS neck pre- and post-operative parameters in the CDTR and ACDF groups was -0.89 with a $95 \%$ CI of $(-2.30 ; 0.52)$ (Figure 6). Such a result indicated higher values of differences for the CDTR; therefore, the patients treated with ACDF had greater benefits with respect to the VAS neck score. This result was not consistent with the results obtained on the basis of the analysis of the collected RCTs and the combined effect of their metaanalysis $[24,28,31]$. In most papers, the average difference in differences was $>0$, which would indicate an advantage to using the CDTR method. The difference obtained for the group did not exceed the MCID threshold determined on the basis of data from the literature [12-15].

In our series, the average difference between the VAS arm parameter values in the pre- and post-operative CDTR and ACDF cohorts was found to be 0.97 with a $95 \% \mathrm{CI}$ equal to $-0.47 ; 2.41$ (Figure 6). Such a result indicated higher values of differences for the CDTR method; therefore, the patients treated with CDTR presented greater benefits than those treated with ACDF. This result was in line with results obtained on the basis of the collected RCT analysis and meta-analysis effects [24,28,31]. In most papers, the average difference in differences was $>0$, which would indicate an advantage to using the CDTR method.
In all of the above assays, accurate analyses were complicated by wide and overlapping CIs.

\section{Discussion}

To the best of our knowledge, our series is the largest prospective series originating within a single center that compared CDTR with ACDF with results available in the literature until the end of 2017. Our series was the only one comparing CDTR to ACDF with the use of resorbable cages. As previously mentioned, anterior cervical discectomy and fusion is considered by some to be the gold standard for the surgical treatment of cervical disc herniation [1,32]. Its efficacy varies from $70 \%$ to $90 \%$ regardless of the method used for the fusion [1]. In this study, we used the clinical data from postADCF patients who had received resorbable cages, which was proposed in the last decade and was regarded as equally effective as standard cages, as a referral tool to evaluate the efficacy of CDTR [4]. Permanent fusion of degenerated segment changes biomechanical conditions and shifts the distribution of forces to adjacent segments, which most likely leads to their accelerated degeneration and the occurrence of ASD $[8,9,33]$. CDTR, in turn, is a technique that is expected to retain mobility in the segment that underwent surgery, which in theory, should reduce the probability of complications such as ASD [10]. Despite the use 
of artificial disc prostheses over the last several years, there has been no clear evidence that such prostheses are preferable to classic ACDF [34]. The superiority of CDTR versus ACDF has been an issue of great controversy for years. Recently, a number of studies have suggested better results after using CDTR in some aspects (such as better functional outcomes, fewer adverse events, and fewer secondary surgical procedures) [35-49]. It should be noted that the differences between both methods were quite small, and the follow-up duration of the analyzed papers was up to five years.

We were also unable to demonstrate without any doubt the superiority of either of these two surgical techniques according to clinical parameters evaluated at the follow-ups. In this regard, our observation is consistent with the previously described publications. The only difference between our series' cohorts was noted in the functional outcome expressed as the EQ-5D index at six months (Table 1) in favor of ACDF. In an analogous manner, the same is valid for the VAS neck (neck pain intensity and frequency) scores at 6 months (Figure 1). A plausible explanation might be the relative hypermobility of the segment that underwent the operation, which might lead to transient increase in neck pain. As the segment that underwent the operation heals over time, poorer outcomes were not observed at longer follow-up durations. We have to admit that we did not find a similar phenomenon in a review of the literature.

The frequency of re-operation related to the appearance of ASD in our study was 1.9\%/level/year in the ACDF group, which is slightly lower than that in the classic study of Hilibrand, which was $2.9 \% /$ level/year [9]. This difference in the findings is likely due to the evolution of surgical techniques and imaging methods over the past 20 years. In the case of CDTR, we achieved a significantly lower frequency of $0.6 \%$ /level/year. A lower incidence of ASD after using CDTR has also been demonstrated in a meta-analysis of Jiang et al. [50], but the authors point out that the quality of included studies was of low quality. A metaanalysis of eight prospective studies by Luo et al. drew similar conclusions [51]. These authors showed that the frequencies of ASD in the ACDF and CDTR groups were $1.31 \%$ and $0.49 \%$ /year, respectively. However, the follow-up time was only 24 months. In a recent meta-analysis of six prospective studies, Verma et al. [52] showed that the occurrence of ASD after ACDF was 2.4\%/ year (SD = 1.7), and the occurrence of ASD after CDTR was $1.1 \% /$ per year $(\mathrm{SD}=1.5)$. In this case, the follow-up time was five years. This difference was statistically insignificant, which indicates that the frequency of ASD in both groups was the same.

The apparent disadvantage of our cohort survey is the lack of full patient randomization. When qualifying for individual cohorts, we assumed that the lack of mobility in the segment that underwent surgery should be a criterion to exclude a patient from the arthroplasty group. We also established that the lack of this mobility should be assessed intraoperatively rather than on the basis of pre-operative functional radiographs, which may give false negative results due to strong neck muscle tension in acute neck pain syndromes. However, it is precisely this difference between the two cohorts resulting from the assumed criterion that enabled us to formulate the assumption that the combination of our results with the results of randomized trials could confirm that our criterion for disqualification from CDTR was the correct choice.

As early as the 24-month follow-up in our series, nine ASD cases requiring the next operation in the ACDF group and none in the CDTR group were recorded (odds ratio $[\mathrm{OR}]=0.5,95 \%$ CI $[0.00 ; 0.94])$ and this result was more favorable for CDTR compared to the result of the meta-analysis $(\mathrm{OR}=0.63,95 \% \mathrm{CI}$ $[0.44 ; 1.03])$.

This trend was maintained over 60 months in which the distinct advantage of ASD over ACDF was observed both for our own series and in all of the analyzed publications. Unfortunately, in our opinion, it seems that these differences do not allow us to make a conclusion about the correctness of our assumption. It is more likely that the above result was influenced by demographic data, which included the criterion of excluding patients with intraoperative segment immobility, and also the fact that patients in the ACDF cohort were on average 10 years older than in the ACDF cohort. This finding makes it appear that patients are more vulnerable to ASD resulting from natural causes. Also, the comparison of our series' results within the scope of other clinical questionnaire parameters with the results from the meta-analysis does not indicate significant differences in the evaluated clinical parameters and therefore does not allow any conclusions to be drawn; however, with respect to the hypothesis that there are no indications for arthroplasty in patients in which we find intraoperative lack of mobility in the segments that underwent surgery, this hypothesis seems exceptionally attractive. Perhaps further, better-designed studies will be able to confirm this hypothesis.

\section{Conclusion}

Our study reveals that CDTR and ACDF are very functionally effective for the treatment of symptomatic CDDD in terms of either early or long-term outcomes. This fact confirms the concept that decompression is the most important factor in the surgical treatment of this disorder. In our study, it was possible to show a statistically significant importance of CDTR for the prevention of ASD, which still remains to be proven in the literature. We hope that such evidence will arrive soon with the publications of long-term results of high quality clinical trials. Based on the comparison of our material with the results of the meta-analysis, we were not able to absolutely prove the correctness of our hypothesis in which the lack of motion in the segment that underwent surgery is a contraindication to CDTR. 


\section{Open Access Journal of Neurology \& Neurosurgery}

\section{Author contributions}

All authors contributed toward data analysis, drafting, and critically revising the paper, gave final approval of the version to be published, and agreed to be accountable for all aspects of the work.

\section{Disclosure}

The authors report no conflicts of interest in this work.

\section{References}

1. Leonardi M, Boos N (2009) Degenerative disorders of the cervical spine. W Boos N, Aebi M (eds). Spinal disorders. Fundamentals of diagnosis and treatment. Berlin-Heidelberg: Springer Verlag, pp. 429507.

2. Latka D, Miekisiak G, Jarmuzek P, Lachowski M, Kaczmarczyk J (2016) Treatment of degenerative cervical spondylosis with radiculopathy. Clinical practical guidelines endorsed by the Polish Society of Spinal Surgery. Neurol Neurochir Pol 50(2): 109-113.

3. Smith GW, Robinson RA (1955) The treatment of certain spine disorders by anterior removal of the intervertebral disc and interbody fusion. J Bone Joint Surg Am 40(3): 607-624.

4. Cao L, Duan P-G, Li X-L, Yuan F-L, Zhao M-D, et al. (2012) Biomechanical stability of a bioabsorbable self-retaining polylactic acid/nano-sized $\beta$-tricalcium phosphate cervical spine interbody fusion device in single-level anterior cervical discectomy and fusion sheep models. Int J Nanomedicine 7: 5875-5880.

5. Nanda A, Sharma M, Sonig A, Ambekar S, Bollam P (2013) Surgical Complications of Anterior Cervical Diskectomy and Fusion for Cervical Degenerative Disk Disease: A Single Surgeon's Experience of 1576 Patients. World Neurosurg 82(6): 1380-1387.

6. Ahn SS, So WS, Ku MG, Kim SH, Kim DW, et al. (2016) Radiologic Findings and Risk Factors of Adjacent Segment Degeneration after Anterior Cervical Discectomy and Fusion: A Retrospective Matched Cohort Study with 3-Year Follow-Up Using MRI. J Korean Neurosurg Soc 59(2): 129-136.

7. Eck JC, Humphreys SC, Lim TH, Jeong ST, Kim JG, et al. (2002) Biomechanical study on the effect of cervical spine fusion on adjacentlevel intradiscal pressure and segmental motion. Spine (Phila Pa 1976) 27: $2431-2434$

8. Tobert DG, Antoci V, Patel SP, Saadat E, Bono CM (2017) Adjacent Segment Disease in the Cervical and Lumbar Spine. Clin Spine Surg 30(3): 94-101.

9. Hilibrand AS, Robbins M (2004) Adjacent segment degeneration and adjacent segment disease: the consequences of spinal fusion? Spine J 6: 190S-194S

10. Basho R, Hood KA (2012) Cervical Total Disc Arthroplasty. Global Spine J 2(2): 105-108.

11. Latka D, Kozlowska K, Miekisiak G, Latka K, Chowaniec J, et al. (2019) Safety and efficacy of cervical disc arthroplasty in preventing the adjacent segment disease. A meta-analysis of mid- to long-term outcomes in prospective randomized controlled multicenter studies. Ther Clin Risk Manag 15: 531-539.

12. Auffinger BM, Lall RR, Dahdaleh NS, Wong AP, Lam SK, et al. (2013) Measuring surgical outcomes in cervical spondylotic myelopathy patients undergoing anterior cervical discectomy and fusion: assesment of minimum clinically important difference. PloS One 8(6): e67408

13. Carreon LY, Glassman SD, Campbell MJ, Anderson PA (2010) Neck Disability Index, short form-36 physical component summary, and pain scales for neck and arm pain: the minimum clinically important difference and substantial clinical benefit after cervical spine fusion. Spine J 10(6): 469-474.

14. Copay AG, Subach BR, Glassman SD, Polly DW, Schuller TC (2007) Understanding the minimal clinically important difference: a review of concepts and methods. The Spine J 7(5): 541-546.

15. McGlothilin AE, Lewis RJ (2014) Minimal clinically important difference: defining what really matters to patients. JAMA 312(13): $1342-1343$

16. Sasso RC, Anderson PA, Riew KD, Heller JG (2011) Results of cervical arthroplasty compared with anterior discectomy and fusion: four year clinical outcomes in a prospective, randomized controlled trial. J Bone Joint Surg Am 93(18): 1684-1692.

17. Mummaneni PV, Burkus JK, Haid RV (2007) Clinical and radiographic of cervical disc arthroplasty compared with allograft fusion: a randomizedcontrolled clinical trial. J Neurosurg Spine 6(3): 198-209.

18. Burkus JK, Traynelis VC, Haid RW Jr, Mummanei PV (2014) Clinical and radiographic analysis of an artificial cervical disc: 7year followup from the Prestige prospective randomized controlled clinical trial: Clinical article J Neurosurg Spine 21(4): 516-528.

19. Coric D, Nunley PD, Guyer RD, Musante D, Carmody CN, et al. (2011) Prospective randomized multicenter study of cervical arthroplasty: 269 patients from the Kineflex-C artificial disc investigational device exemption study with minimum 2 yrs follow-up: clinical article. J Neurosurg Spine 15: 348-358.

20. Gornet MF, Burkus JK, Shaffrey ME, Argires PJ, Nian H, et al. (2015) Cervical arthroplasty with PRESTIGE LP discus versus anterior cervical discectomy and fusion: a prospective, multicenter investigational device excemption study. J Neurosurg Spine 23(5): 558-573.

21. Gornet MF, Lanman TH, Burkus JK, Hodges SD, McConnel JR, et al. (2017) Cervical disc arthroplasty at two levels with PRESTIGE LP disc versus anterior cervical discectomy and fusion: results of a prospective, multicenter pivotal clinical trial at twenty four months. J Neurosurg Spine 26(6): 653-667.

22. Phillips FM, Lee JYB, Geisler FH, Cappucino A, Chaput CD, et al. (2013) A prospective randomized controlled clinical investigation comparing PCM cervical disc arthroplasty with anterior cervical discectomy and fusion. 2-years results from the US FDA IDE clinical trials. Spine 38(15): E907-E918.

23. Skeppholm M, Lindgren L, Henriques T, Vavruch L, Loefgren $\mathrm{H}$, et al (2015) The Discover artificial disc replacement versus fusion i $n$ cervical radiculopathy - a randomized controlled outcome trial with 2-year follow up. The Spine J 15(6): 1284-1294.

24. Janssen ME, Zigler JE, Spivak JM, Delamarter RB, Darden BV, et al. (2015) Prodisc-C total disc replacement versus anterior cervical discectomy and fusion for single level symptomatic cervical disc disease: seven year follow-up of the prospective randomized U.S. Food and Drug Administration Investigational Device Exemption Study. J Bone Joint Surg Am 97(21): 1738-1747.

25. Hisey MS, Zigler JE, Jackson R, Nunley PD, Bae HW, et al. Prospective randomized comparison of one level Mobi-C cervical total disc replacement vs. anterior cervical discectomy and fusion: results at 5 year follow up. Int J Spine Surg 10: 10.

26. Jackson RJ, Davis RJ, Hoffman GA, Bae HW, Hisey MS, et al. (2016) Subsequent surgery rates after cervical total disc replacement using a Mobi-C Cervical Disc Prothesis versus anterior cervical discectomy and fusion: a prospective randomized clinical trial with 5-year follow up. J Neurosurg Spine 24(5): 734-745.

27. Murrey D, Janssen M, Delamarter R, Goldstein J, Zigler J, et al. (2009) Results of the prospective, randomized, controlled multicenter Food and Administration investigational device exemption study of the 
Prodisc- $C$ total disc replacement versus anterior discectomy and fusion for the treatment of 1-level symptomaticervical disc disease. Spine J 9(4): 275-286.

28. Zhang X, Zhang X, Chen C, Zhang Y, Wang Z, et al. (2012) Randomized, controlled, multicenter clinical trial comparing Bryan cervical disc arthroplasty with anterior cervical decompression and fusion in China Spine 37(6): 433-438.

29. Radcliff K, Lerner J, Yang C, Bernard T, Zigler JE (2016) Seven-year cost-effectiveness of ProDisc- $C$ total disc replacement: results from investigational device exemption and postr-approval studies. J Neurosurg Spine 24(5): 760-768.

30. Heller JG, Sasso RC, Papadopoulos SM, Anderson PA, Fesler RG, et al. (2009) Comparison of BRYAN cervical disc arthroplasty with anterior cervical decompression and fusion: clinical and radiographic results of the randomized, controlled clinical trial. Spine (Phila Pa 1976) 34(2) 101-107.

31. Davis RJ, Kim KD, Hisey MS, Hoffman GA, Bae HW, et al. (2013) Cervical total disc replacement with Mobi-C cervical articficial disc compared with anterior discectomy and fusion for treatment of 2-level symptomatic degenerative disc disease: a prospective, randomized, controlled multicenter clinical trial: clinical article. J Neurosurg Spine 19(5): 532-545.

32. Rao RD, Currier BL, Albert TJ, Bono CM, Marawar SV, et al. (2007) Degenerative cervical spondylosis: clinical syndromes, pathogenesis, and management. Instr Course Lect 57: 447-469.

33. Luo J, Gong M, Huang S, Yu T, Zou X (2015) Incidence of adjacent segment degeneration in cervical disc arthroplasty versus anterior cervical decompression and fusion meta-analysis of prospective studies Arch Orthop Trauma Surg 135(2): 155-160.

34. Le H, Thongtrangan I, Kim DH (2004) Historical review of cervical arthroplasty. Neurosurg Focus 17(3): E1.

35. Ma Z, Ma X, Yang H, Guan X, Li X (2017) Anterior cervical discectomy and fusion versus cervical arthroplasty for the management of cervical spondylosis: a meta-analysis. Eur Spine J 26(4): 998-1008.

36. Muheremu A, Niu X, Wu Z, Muhanmode Y, Tian W (2015) Comparison of the short- a nd long-term treatment effect of cervical replacement and anterior cervical disk fusion: a meta-analysis. Eur J Orthop Surg Traumatol 25: S87-S100.

37. Rao MJ, Nie SP, Xiao BW, Zhang GH, Gan XR, et al. (2015) Cervical disc arthroplasty versus anterior cervical discectomy and fusion for treatment of symptomatic cervical disc disease: a meta-analysis of randomized controlled trials. Arch Orthop Trauma Surg 135(1): 19-28.

38. Ren C, Song Y, Xue Y, Yang X (2014) Mid- to longterm outcomes after cervical disc arthroplasty compared with anterior discectomy and fusion: a systematic review and meta-analysis of randomized controlled trials. Eur Spine J 23(5): 1115-1123.

39. Shriver MF, Lubelski D, Sharma AM, Steinmetz MP, Benzel EC, et al (2016) Adjacent segment degeneration and disease following cervical arthroplasty: a systematic review and meta-analysis. Spine J 16(2): 168-181.
40. Wu AM, Xu H, Mullinix KP, Jin HM, Huang ZY, et al. (2015) Minimum 4-year outcomes of cervical total disc arthroplasty versus fusion: a metaanalysis based on prospective randomized controlled trials. Medicine 94(15): e665.

41. Xie L, Liu M, Ding F, Li P, Ma D (2016) Cervical disc arthroplasty (CDTR) versus anterior cervical discectomy and fusion (ACDF) in symptomatic cervical degenerative disc diseases (CDDDs): an updated meta-analysis of prospective randomized controlled trials (RCTs). SpringerPlus 5(1): 1188.

42.Xing D, Ma XL, Ma JX, Wang J, Ma T, et al. (2013) A meta-analysis of cervical arthroplasty compared to anterior cervical discectomy and fusion for single-level cervical disc disease. J Clin Neurosci 20(7): 970978.

43. Xu B, Ma J, Tian J, Ge L, Ma X (2017) Indirect meta-analysis comparing clinical outcomes of total cervical disc replacements with fusions for cervical degenerative disc disease. Sci Rep 7(1): 1740.

44. Yang B, Li H, Zhang T, He X, Xu S (2012) The incidence of adjacent segment degeneration after cervical disc arthroplasty (CDTR): a meta analysis of randomized controlled trials. PLoS One 7(4): e35032.

45. Yao Q Liang F, Xia Y, Jia C (2016) A metaanalysis comparion total disc arthroplasty with anterior cervical discectomy and fusion for the treatment of cervical degenerative diseases. Arch Orthop Trauma Surg 136(3): 297-304.

46. Yin S, Yu X, Zhou S, Yin Z, Qiu Y (2013) Is cervical disc arthroplasty superior to fusion for treatment of symptomatic cervical disc disease? A metaanalysis. Clin Orthop Relat Res 471(16): 1904-1919.

47. Young IA, Cleland JA, Michener LA, Brown C (2010) Reliability, construct validity and responsivenes of the neck disability index, patient-specific functional scale and numeric pain rating scale in patients with cervical radiculopathy. Am J Phys Med Rehab 89(10): 831-839.

48. Yu L, Song Y, Yang X, Lv C (2011) Systematic review and meta-analysis of randomized controlled trials: comparison of total disc replacement with anterior decompression. Orthopedics 34(10): e651-e658.

49.Zeichmeister I, Winkler R, Mad P (2011) Artificial total disc replacement versus fusion for the cervical spine: a systematic review. Euro Spine J 20(2): 177-184.

50. Jiang H, Zhu Z, Qiu Y, Qian B, Qiu X, et al. (2012) Cervical disc arthroplasty versus fusion for single-level symptomatic cervical disc disease: a meta-analysis of randomized controlled trials. Arch Orthop Trauma Surg 132(2): 141-151.

51. Luo J, Gong M, Huang S, Yu T, Zou X (2015) Incidence of adjacent segment degeneration in cervical disc arthroplasty versus anterior cervical decompression and fusion meta-analysis of prospective studies. Arch Orthop Trauma Surg 135(2): 155-160.

52. Verma K, Gandhi SD, Maltenfort M, Albert TJ, Hilibrand AS, et al. Rate of adjacent segment disease in cervical disc arthroplasty versus singlelevel fusion: meta-analysis of prospective studies. Spine 38(26): 22532257. 
(C) This work is licensed under Creative BY DOI: 10.19080/OAJNN.2019.11.555805

\section{Your next submission with Juniper Publishers will reach you the below assets}

- Quality Editorial service

- Swift Peer Review

- Reprints availability

- E-prints Service

- Manuscript Podcast for convenient understanding

- Global attainment for your research

- Manuscript accessibility in different formats

( Pdf, E-pub, Full Text, Audio)

- Unceasing customer service

Track the below URL for one-step submission

https://juniperpublishers.com/online-submission.php 